\title{
Usher syndrome: reason for combined hearing and vision loss
}

\begin{abstract}
Usher syndrome (US), also known as, retinitis pigmentosa-dysacusis syndrome, is an rare genetic condition but represents the most common cause of inherited combined vision and hearing loss. It is inherited in an autosomal recessive pattern. There are many gene proteins have been identified, that all of them are very important for the function of the inner ear stereocilia . Early and accurate detection of US is crucial and it is generally performed through hearing, balance, vision tests and genetic study. This study is a brief clinical and genetic analysis of US patients.
\end{abstract}

Keywords: usher, sensorineural hearing loss ,retinitis pigmentosa, clinical genetics
Volume 10 Issue 3 - 2018

\section{Erdem Atalay Cetinkaya, I Mehmet Fatih \\ Kucuk2}

'ENT Department, Antalya Ataturk State Hospital, Turkey

${ }^{2}$ Ophthalmology Department, Antalya Ataturk State Hospital, Turkey

Correspondence: Erdem Atalay Cetinkaya, ENT Department, Antalya Ataturk Devlet Hastenesi, KBB Klinigi,Antalya, 07000 Turkey, Tel 009053341। 0305,

Email drerdemcetinkaya@gmail.com

\section{Introduction}

The aim of this study is to present a case of progresive sensorineural hearing loss with deterioration of visual acuity. Usher syndrome (US) is a rare but the most common cause of inherited combined vision and hearing loss. In order to establish a recent diagnosis of US genetic examination must be performed. Early detection for US in children with sensorineural hearing loss is very important. Psychological, educational and sociological assistance is also important. The patient may develop symptoms of retinitis pigmentosa in second or third decade of his life. The necessity of thorough investigation for detecting other systemic abnormalities should be emphasized. There is no efficient treatment of this syndrome.

\section{Case presentation}

A 45-year-old Caucasian man with high frequency sensorineural hearing loss (Figure 1) and deterioration of visual acuity. He gave a history of hearing loss for 10 years. His medical history was not significant and denied a history of ocular or head trauma, taking any medications. There is no family history. He underwent standard ENT and ophthalmologic examination. Visual field examination disclosed peripheral ring scotoma. Electrophysiological studies was performed Ophthalmoscopy (Figure 2) demonstrated pigment in the retina. The presence of progresive sensorineural hearing loss indicated the necessity of performing the genetic study for US. Apart from a mild loss in visual acuity that had been relatively stable for several years, our patient did not have any other significant ocular symptoms.

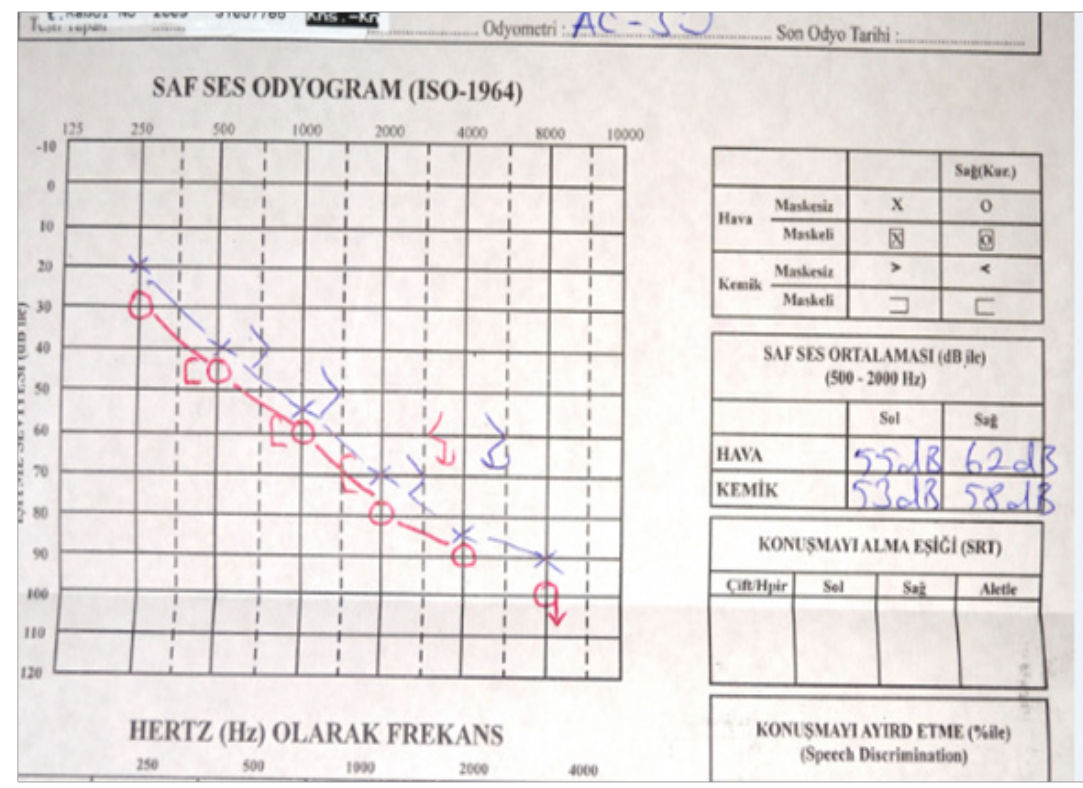

Figure I Pure tone audiometry presents bilateral moderetaly severe high frequency sensorineural hearing loss. 


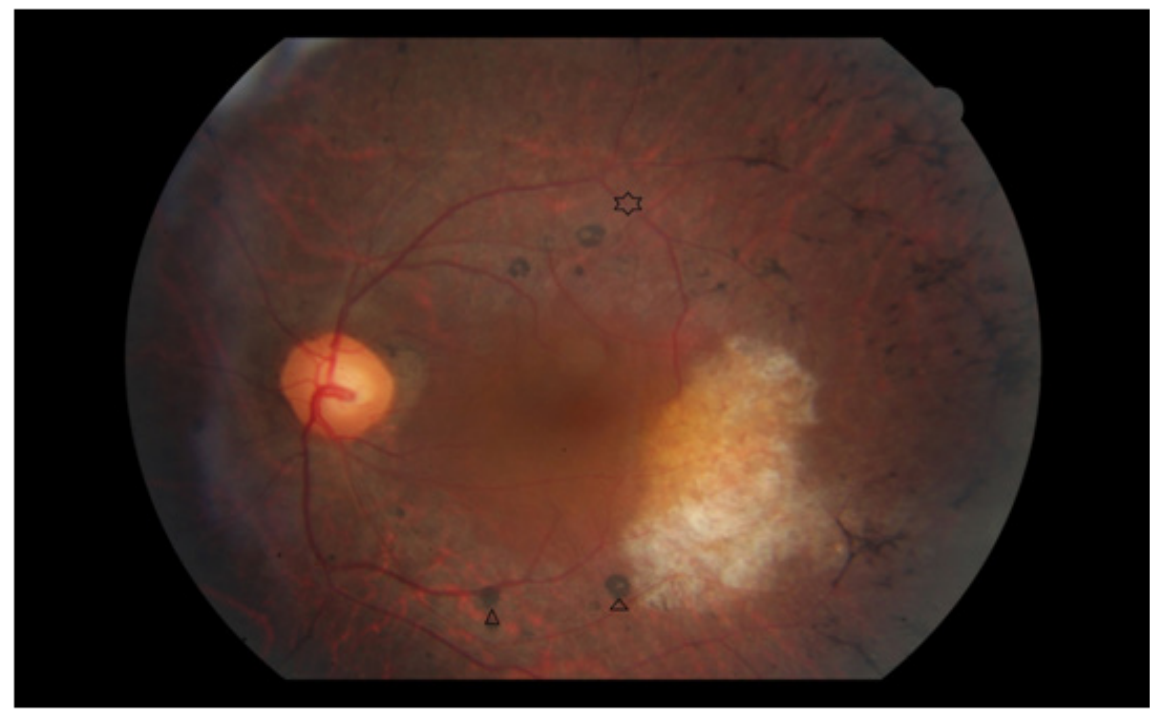

Figure 2 Photograph of the retina of a patient The optic nerve looks pale, the vessels $(*)$ are very thin and there is characteristic pigment, called bone spicules $(\wedge)$.

\section{Discussion}

US, also known as, retinitis pigmentosa-dysacusis syndrome, is an rare genetic condition but represents the most common cause of inherited combined vision and hearing loss.. It is a leading cause of incurable blindness.1Many studies have proposed $10 \%$ of congenitally deaf children may have US. ${ }^{1}$ It is inherited in an autosomal recessive pattern and named after the Scottish ophthalmologist Charles Usher in $1914 .^{2}$

The hearing loss is induced by a malformed inner ear hair cells. Up to date, there are 11 US proteins have been identified, that all of them are very important for the function of the mechanosensory cells of these cells. Also these proteins are placed to the stereocilia of the hair cells, where mechanoelectrical transduction of sound-induced vibrations happens. ${ }^{1-3}$

The progressive blindness of US results from retinitis pigmentosa The photoreceptor cells usually start to degenerate from the outer periphery to the center of the retina, including the macula. The degeneration is usually first noticed as nyctalopia (night blindness); tunnel vision (restricting the visual field). The identifier 'pigmentosa' reflects may be visible in advanced stages of degeneration.,

US is a variable conditionand has four clinical types, represented as type I, II, III and IV. ${ }^{6}$ Patients with US type I are born hard of hearing, and begin to lose their vision in the first decade of life. They also present balance problems and able to walk slowly as children, because of in their vestibular system deficiency. This type I can be caused by mutations in genes: CDH23, MYO7A, PCDH15, USH1C, and USH1G genes. These genes function in the development and maintenance of stereocilia, which transmit sound and motion signals to the brain. ${ }^{7,8}$

Patients with US type II are not born deaf, but do have hearing loss. They do not seem to have noticeable problems with vestibular dysfunction; they also lose their vision later into middle age. This type can be caused by mutations in any of USH2A, GPR98, and DFNB31 genes. The crucial protein encoded by the USH2A gene, usherin, is located in the supportive tissue in the retina and inner ear. ${ }^{9,10}$

Patients with US type III are not born deaf, but experience a gradual loss of their hearing and vision; they may or may not have their vestibular system deficiency. This type may be unaffected in childhood, but go on to develop a profound hearing loss and a very significant loss of sight by early to third decade. Mutations in one gene, $C L R N$, have been linked to this type . CLRN1 encodes clarin-1, a protein crucial for the development and maintenance of the retina and inner ear. ${ }^{11,12}$

US type IV, X-linked inheritance, but phenotype is similar to that of type II. ${ }^{13}$

Early detection of US with an accurate diagnosis is crucial and it is generally performed through hearing, balance, and vision tests. Evaluation of patients may include a retinal examination, visual field tests, audiologic evaluation, and an electronystagmogram. An alternative approach is electroretinography, however it is often disfavored for children. The basic approach to accurate diagnosing US is to test for the characteristic chromosomal mutations.

A misdiagnosis can have bad results. There are many syndromes can present similar signs to US, such as Alport syndrome, Alstrom syndrome, Bardet-Biedl syndrome, Cockayne syndrome, spondyloepiphyseal dysplasia congenita, Flynn-Aird syndrome, Friedreich ataxia, Hurler syndrome, Kearns-Sayre syndrome, Norrie syndrome, osteopetrosis (Albers-Schonberg disease), Refsum's disease, and Zellweger syndrome (cerebrohepatorenal syndrome). ${ }^{1,2,5}$

The earlier that child has US, the sooner that child can begin special educational training programs to manage the hearing and vision problems. Typically, treatment will include hearing aids, cochlear implants, assistive listening devices or other communication methods. Seeing that US results from the loss of a gene, gene replacement 
therapy that adds the proper protein back may relieve it, provided the added protein becomes functional. Recent studies of animal models have shown that associated with a mutation in MYO7A can be relieved by replacing the altered gene using a lentivirus. ${ }^{14}$

\section{Conclusion}

US is an rare but the most common cause of autosomal recessive inherited combined vision and hearing loss. There are many gene proteins have been identified, that all of them are very important for the function of the inner ear stereocilia . Early and accurate detection of US is crucial.

\section{Acknowledgements}

None.

\section{Conflict of interest}

The author declares no conflict of interest or external financing.

\section{References}

1. Mets MB, Young NM, Pass A, et al. Early diagnosis of Usher syndrome in children. Trans Am Ophthalmol Soc. 2000;98:237-42.

2. Otterstedde CR, Spandau U, Blankenagel A, et al. A new clinical classication for Usher's syndrome based on a new subtype of Usher's syndrome type I. Laryngoscope. 2001;111(1):84-86.

3. Williams DS. Usher syndrome: Animal models, retinal function of Usher proteins, and prospects for gene therapy. Vision Res. 2007;48(3):433-41.

4. Smith RJ, Berlin CI, Hejtmancik JF, et al. Clinical diagnosis of the Usher syndromes. Usher Syndrome Consortium. Am J Med Genet. 1994;50(1):32-38.
5. Fishman GA, Kumar A, Joseph ME, et al. Usher's syndrome. Archives of Ophthalmology. 1983;01(9):1367-1374.

6. Saihan Z, Webster AR, Luxon L, et al. Update on Usher syndrome. Curr Opin Neurol. 2009;22(1):19-27.

7. Millan JM, Aller E, Jaijo T, et al. An update on the genetics of usher syndrome. J Ophthalmol. 2011; 417217.

8. Weil D, Blanchard S, Kaplan J, et al. Defective myosin VIIA gene responsible for Usher syndrome type 1B. Nature. 1995;374(6517):60-1.

9. Weil D, El-Amraoui A, Masmoudi S, et al. Usher syndrome type I G (USH1G) is caused by mutations in the gene encoding USH1G, a protein that associates with the USH1C protein, harmonin. Hum Mol Genet. 2003;12(5):463-71.

10. Riazuddin S, Nazli S, Ahmed ZM, et al. Mutation spectrum of MYO7A and evaluation of a novel nonsyndromic deafness DFNB2 allele with residual function. Hum Mutat. 2008;29(4):502-11.

11. Zou J, Mathur PD, Zheng T, et al. Individual USH2 proteins make distinct contributions to the ankle link complex during development of the mouse cochlear stereociliary bundle. Hum Mol Genet. 2015;24(24):6944-57.

12. Geng R, Omar A, Gopal SR, et al. Modeling and Preventing Progressive Hearing Loss in Usher Syndrome III. Scientific Reports. 2017;18;7(1):13480

13. Lee KJ. Lee's Essential Otolaryngology 11th edn. McGraw Hill Professional, 2015. p. 336.

14. Hashimoto T, Gibbs D, Lillo C, et al. Lentiviral gene replacement therapy of retinas in a mouse model for Usher syndrome type 1B. Gene Ther. 2007;14(7):584-594. 